'Laboratorio de Investigación en Ciencias Biomédicas, Departamento de Ciencias Básicas y Morfología, Facultad de Medicina, Universidad Católica de la Santísima Concepción. Concepción, Chile. 22Dirección Servicio de Salud Concepción. Concepción, Chile. ${ }^{3}$ George Washington Cancer Center, Washington DC, USA

${ }^{4}$ Departamento de Investigación del Cáncer Fundación Arturo López Pérez. Santiago, Chile.

aAlumno de Medicina, Facultad de Medicina, Universidad Católica de la Santísima Concepción. Concepción, Chile.

bAlumno de Bioquímica, Facultad de Farmacia, Universidad de Concepción. Concepción, Chile. 'Bioquímico.

${ }^{d}$ PhD. Doctor en Ciencias Biológicas.

Trabajo financiado por Proyecto UCSC DIN Regular 2019/05 (MIH). Proyecto FONDECYT de Iniciación $11190287(\mathrm{MIH})$

Los autores declaran no tener conflictos de interés.

Recibido el 3 de junio de 2019, aceptado el 12 de marzo de 2020

Correspondencia a: Dr. Matías I. Hepp (M.I. Hepp) Laboratorio de Investigación en Ciencias Biomédicas, Departamento de Ciencias Básicas y Morfología, Facultad de Medicina. Universidad Católica de la Santísima Concepción. Concepción, Chile. mhepp@ucsc.cl

\section{Actualización general de inmunoterapia en cáncer}

\author{
SEBASTIÁN J. REYES ${ }^{1, a}$, KONSTANZA B. GONZÁLEZ \\ CONSTANZA RODRÍGUEZ ${ }^{1, \mathrm{a}}$, CAMILA NAVARRETE-MUÑOZ ${ }^{1, \mathrm{~b}}$, \\ ANDREA P. SALAZAR ${ }^{2}$, ALEJANDRO VILLAGRA ${ }^{3, c, d,}$, \\ CHRISTIAN CAGLEVIC ${ }^{4}$, MATÍAS I. HEPP ${ }^{1, c, d}$
}

\section{Cancer immunotherapy: an update}

Cancer is one of the leading causes of death worldwide. The success rate of conventional anticancer therapeutic approaches such as chemotherapy is limited by the non-specific toxicity and low specificity towards specific tumors, which are highly dependent on the mutational burden present on each patient. Similarly, targeted therapies have proven to induce resistance in numerous malignancies. Therefore, immunotherapy has emerged as a better approach to discriminate between "the own" and "the non-own", which occurs through two types of mechanisms, innate and acquired immunity. Acquired immunity is one of the targets for new immunotherapeutic treatments, unleashing the power of antigen-specific $T$ cells as a potential therapeutic weapon for cancer treatment. Thus, immunotherapy modifies the own immune system to increase the recognition and elimination of cancer cells by identifying these cancer antigens. One of the advantages of immunotherapy, when compared to conventional anticancer approaches, is the generation of long-term immunity (immunological memory). Currently, there are different potential types of immunotherapy in cancer to promote the modulation of the immune response. Among them, the use of cytokines, vaccines, viruses, monoclonal antibodies, and the generation of adaptive immune response cells have achieved successful results in some types of cancer.

(Rev Med Chile 2020; 148: 970-982)

Key words: Immunotherapy; Immune System; Neoplasms.

\section{Cáncer}

0 e define cáncer como un conjunto de enfermedades con características comunes, las cuales se originan por la acumulación de modificaciones genéticas en una célula que pierde los mecanismos de control de la proliferación y sobrevivencia. Se han descrito más de 200 tipos diferentes de cáncer, los que afectan a cualquier órgano del cuerpo, con síntomas y tratamientos distintos ${ }^{1}$.

Estas desregulaciones se deben a factores genéticos heredados, o factores externos como: tabaco, alcohol, obesidad, exposición a radiación, etc.
Estos factores, pueden generar procesos celulares como: 1) hiperproliferación celular; 2) evasión de factores supresores de crecimiento; 3 ) activación de invasión y metástasis; 4) inmortalidad replicativa; 5) inducción de angiogénesis y 6) resistencia a apoptosis, conocidos como los sellos distintivos del cáncer (hallmarks) ${ }^{2,3}$, vinculados con el control del ciclo celular.

Aunque el ciclo celular esté regulado adecuadamente, el ADN puede sufrir alteraciones genéticas, en genes reparadores, genes supresores de tumores y oncogenes. Esto conlleva desregulación de varios procesos, generando activación de 
protooncogenes, inactivación de genes supresores de tumores o ambos ${ }^{3}$.

Cuando no hay equilibrio entre la proliferación y la apoptosis, aumenta el riesgo de tumorigénesis, y las células neoplásicas crecen sin control. Aquí aparecen otras propiedades de las células cancerosas, como desplazarse y colonizar sectores del organismo, generando metástasis o invasión celular. Estas células cancerígenas, además, podrían activar a células endoteliales y generar angiogénesis para poder nutrirse, lo que produciría crecimiento tumoral ${ }^{3,4}$.

A los sellos distintivos del cáncer ya mencionados, se incorporan 4 procesos emergentes en la formación y mantención del cáncer ${ }^{2}$, generando procesos que modifican el contexto celular. Dos de estos apuntan a facilitar la aparición de los marcadores principales. Uno es la inestabilidad genómica, lo que confiere a las células cancerosas alteraciones genéticas que conducen a progresión tumoral. El otro, producir inflamación por células inmunes innatas diseñadas para combatir infecciones o sanar heridas, dando lugar a procesos que son promotores de respuesta inflamatoria tumoral. Los otros dos mecanismos son focos emergentes directos. Siendo uno, el modificar o reprogramar el metabolismo celular para favorecer la proliferación neoplásica. El otro es la evasión de células cancerosas a destrucción inmunológica, por linfocitos $\mathrm{T}$ y B, macrófagos y natural killers $(\mathrm{NK})^{2}$, generándose blancos terapéuticos diferentes a los convencionales. Existen muchos tratamientos para el cáncer, pero los convencionales (cirugía, radiación y quimioterapia) siguen siendo más utilizados, y aún efectivos, pero invasivos y tóxicos. El tratamiento se selecciona según el tipo de tumor, estadio de enfermedad y condiciones del paciente ${ }^{4}$. La tasa de éxito de los tratamientos convencionales está limitada por la toxicidad y la no especificidad para el tipo de tumor ${ }^{3}$. En el mundo científico se abre espacio para terapias emergentes, como utilizar la respuesta inmune como mecanismo terapéutico ${ }^{5,6}$. Pero ¿cómo se podría abordar la respuesta inmunológica? Para esto, primero debemos entender en qué consiste.

\section{Respuesta inmunológica}

La respuesta inmunológica se refiere a cómo el sistema inmune permite discriminar "lo propio" de "lo no-propio". La inmunología es el estudio del sistema inmune, es decir, el conjunto de órganos, tejidos y células que tienen como objetivo diferenciar lo propio de lo ajeno. Además, la capacidad de mantener tolerancia o ausencia de respuesta frente a antígenos propios, para desencadenar respuesta efectiva frente a un antígeno, según su naturaleza. Se producen dos tipos de respuestas, según el tipo de sistema inmune: innata (SII) y adquirida (SIA) ${ }^{7}$.

El SII es la primera línea de defensa ante un antígeno. Se caracteriza por actuar tempranamente y reacciona frente a patrones moleculares asociados a patógenos, pero no genera memoria. En cambio, el SIA integra respuestas mediadas por linfocitos, tanto celular (linfocitos T), como humoral (linfocitos B), que, al interactuar con un antígeno, se diferencia a célula plasmática productora de inmunoglobulinas, y según el antígeno se determinará el tipo de inmunoglobulina secretada, por lo que el SIA desencadena una respuesta más específica, diversa y especializada frente a diferentes antígenos y genera memoria ${ }^{7,8}$.

Ocasionalmente, puede existir un desequilibrio en el sistema inmune que impide su correcta función. Ante esto se generaron terapias dirigidas al sistema inmunológico, llamadas inmunoterapia. Estas "modulan" el sistema inmune (potenciar, reconstituir o suprimir una función) cuando sufre un desbalance del funcionamiento ${ }^{8}$.

La inmunoterapia se refiere a una variedad de terapias que incluye cualquier tratamiento que modula la respuesta inmune. Se utilizan fármacos, generalmente elaborados desde materiales de origen biológico, los cuales permiten recuperar funciones alteradas del sistema inmunológico, siendo utilizada en diversos campos, como la alergología, trastornos autoinmunes y, recientemente, cáncer ${ }^{9}$.

\section{Inmunoterapia en cáncer}

Inmunoterapia se refiere a tratamientos que buscan tener efecto antitumoral, mejorando la respuesta inmunológica del paciente frente al tumor, a diferencia de tratamientos convencionales que tratan de afectar directamente al tumor. El rol del sistema inmunitario en cáncer no fue considerado por décadas, pues las células cancerígenas suprimen la respuesta inmunológica hacia ellas mediante activación de vías reguladoras negativas, impidiendo el correcto funcionamiento del sistema inmunológico ${ }^{9}$. 
La inmunoterapia en cáncer consiste en uso de fármacos que ayudan al sistema inmunológico de un paciente, reconociendo y destruyendo de manera eficiente las células cancerosas. Sin embargo, en la actualidad, la definición más reconocida de inmunoterapia en cáncer es cualquier tratamiento que busque reducir la carga tumoral y genere memoria ${ }^{5,6,10-12}$. La inmunoterapia estimula el sistema inmunológico para que reaccione contra los tumores, incluyendo, según utilización, de menor a mayor, uso de moléculas no específicas, vacunas, virus, terapia celular adaptativa y anticuerpos monoclonales inhibidores de puntos de control ${ }^{10-13}$. Estas terapias se detallan a continuación y se resumen algunos puntos en la Tabla 1.

\section{Moléculas no específicas}

Se refieren a citoquinas, que son proteínas solubles que median la comunicación entre células. Nace de las potentes actividades antitumorales de varias citoquinas proinflamatorias en modelos animales, la investigación clínica condujo a la aprobación de interleuquina-2 (IL-2) e interferón (IFN) recombinante para el tratamiento de varias neoplasias malignas, incluso si la eficacia era baja ${ }^{14}$.

\section{- Interleuquina-2 (IL-2)}

Generan señales que influyen sobre varios subconjuntos de linfocitos durante la diferenciación, respuesta inmunitaria y homeostasis. La estimulación con IL-2 es crucial para el mantenimiento de los linfocitos T reguladores y para la diferenciación de linfocitos T CD4+. Para los linfocitos T CD8+, las señales de IL-2 optimizan tanto la generación de linfocitos $\mathrm{T}$ efectores como la diferenciación en linfocitos de memoria. El uso de IL-2, ya sea solo o en un complejo con anticuerpos inhibidores específicos de IL-2, puede amplificar las respuestas de linfocitos T CD8+ o inducir la expansión de la población celular, favoreciendo así la estimulación o la supresión inmunitaria ${ }^{14,15}$. Hoy en día la utilidad clínica es mínima, por la alta toxicidad y letalidad asociada a esta terapia.

\section{- Interferón (IFN)}

Estos activan la vía de señalización JAK-STAT. IFN- $\alpha$ e IFN- $\beta$ estimulan la actividad de proteínas JAK1 y TYK2, lo que conduce a fosforilación de STAT1 y STAT2, y en última instancia inducen secreción de IL-4 y activación posterior de lin- focitos B. El IFN- $\alpha$ también causa apoptosis de células tumorales de una manera dependiente de caspasas $^{16}$. El IFN- $\alpha$ fue aprobado como tratamiento adyuvante para pacientes con melanoma de alto riesgo, para utilizarlo en terapias dirigidas. Aunque estos ensayos mostraron una mejoría en la supervivencia inicial, los datos de seguimiento a largo plazo llevaron a concluir que, con un tiempo de seguimiento más prolongado, las curvas de supervivencia libre de recaída y la supervivencia general no demostraban diferencias significativas para IFN- $\alpha$ sobre los controles ${ }^{14,16}$.

\section{Vacunas}

El objetivo de las vacunas es provocar una respuesta inmune antitumoral ${ }^{17}$, lo cual genera una potente respuesta de células $T$ específica para cada tumor, evitando que las células normales sean afectadas ${ }^{17}$.

Existen principalmente dos tipos de vacunas para el cáncer: a) dirigida a prevenir la aparición $\mathrm{y}$ atacar el factor gatillante $\mathrm{y} b$ ) dirigida a tratarlo, incrementando la respuesta del sistema inmunitario contra las células cancerosas ${ }^{18-20}$.

Principalmente, las vacunas dirigidas al tratamiento se clasifican según el tipo de antígeno al que van dirigidas ${ }^{17}$.

Vacunas alogénicas: Células inmunes tumorales aisladas del tumor de un paciente son tratadas y luego administradas a otro paciente para estimular la respuesta inmune citotóxica en un tumor similar.

Vacunas peptídicas: Usan péptidos o proteínas como antígenos no específicos para un tipo de tumor.

Vacunas autólogas: Células inmunes aisladas de un paciente se cultivan y se expone al tumor, generando presentación de antígeno en células dendríticas. Luego, estas se inyectan al paciente, donde deberían activar respuesta inmune sobre las células cancerosas.

Vacunas de ADN: Usan ADN como antígeno, así se genera la expresión de un gen específico.

Vacunas de vectores: Estos vectores pueden ser de restos virales, bacterianos, de levadura u otras estructuras que pueden usarse como antígenos en el anfitrión. 


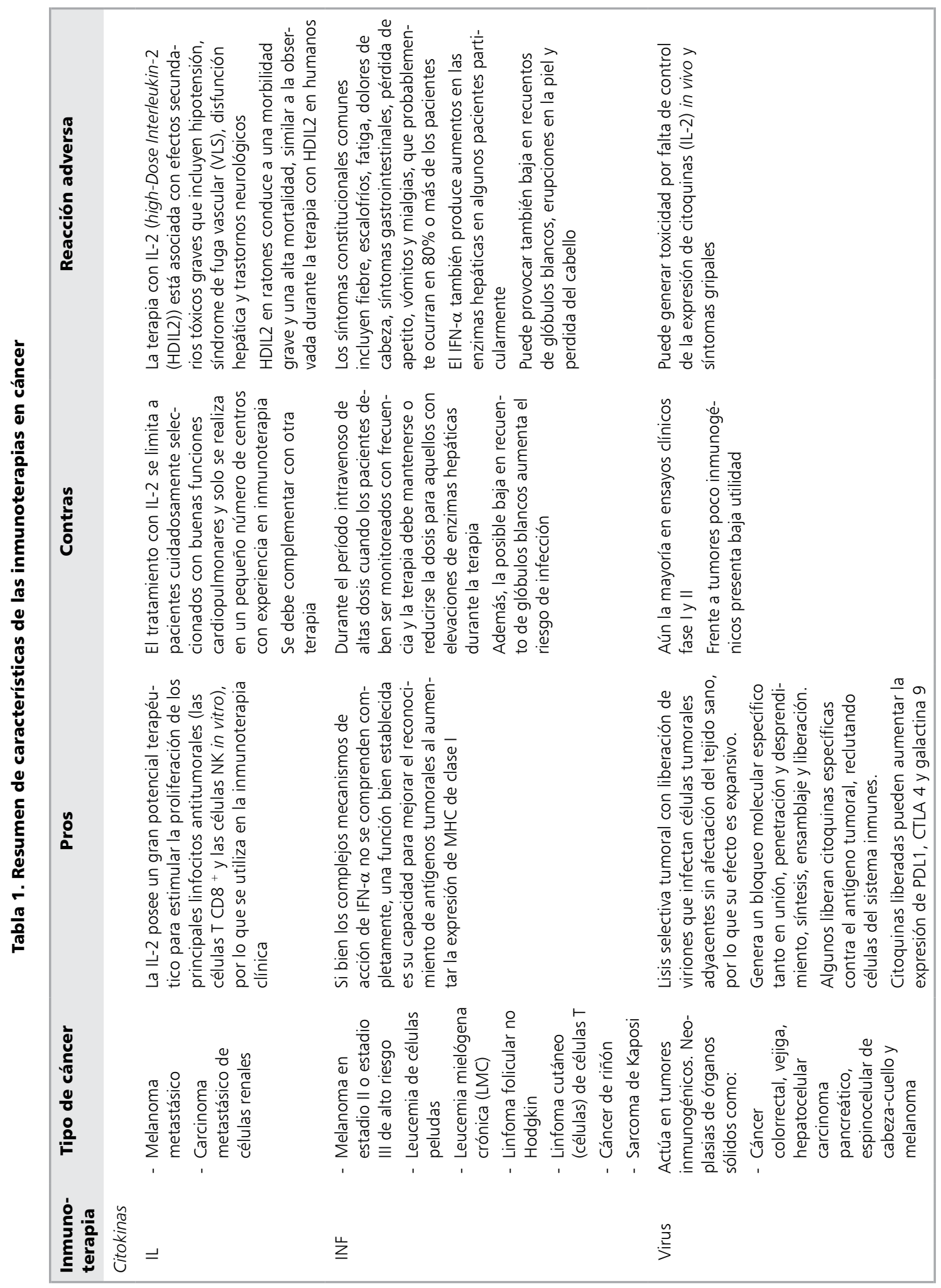




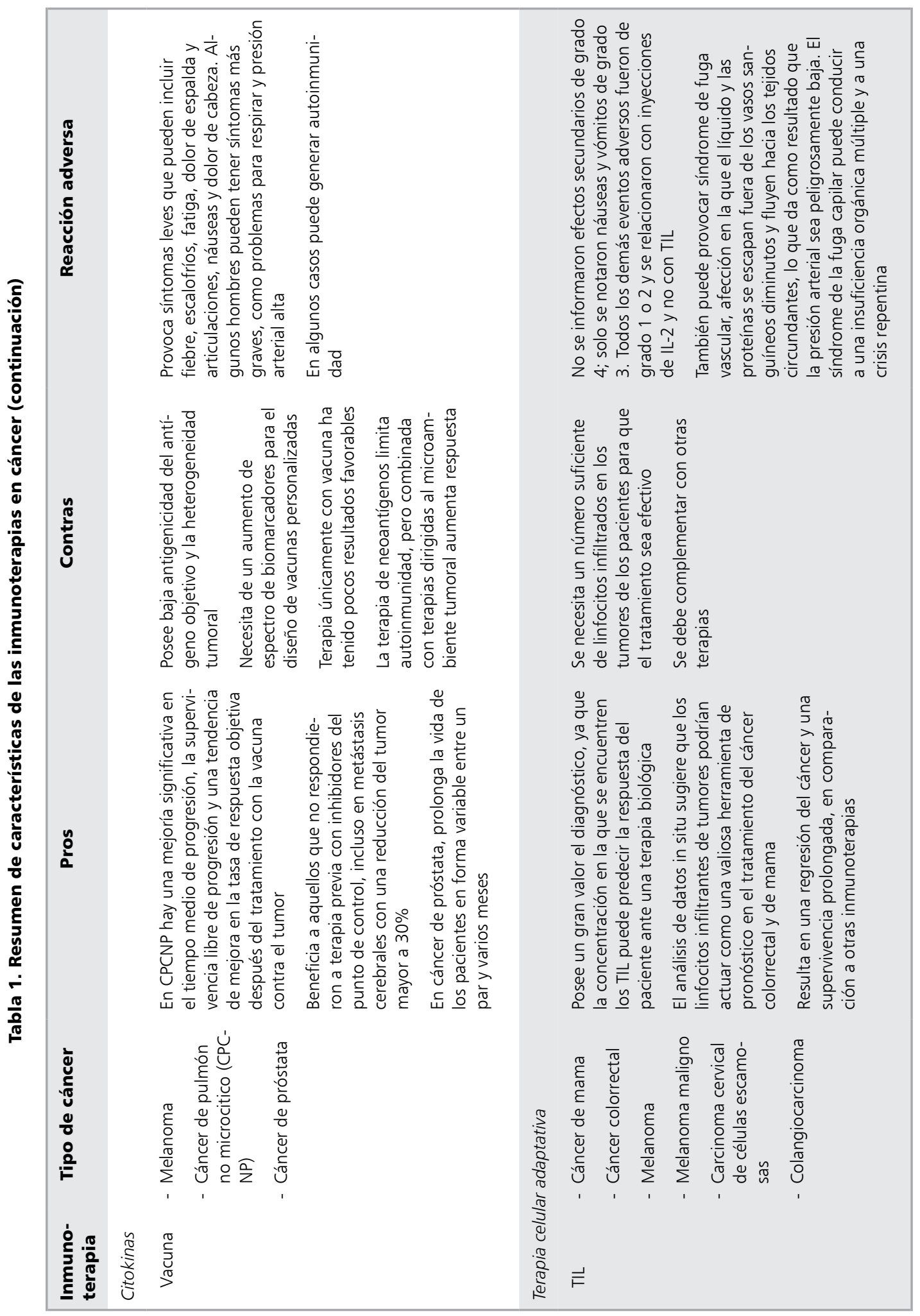




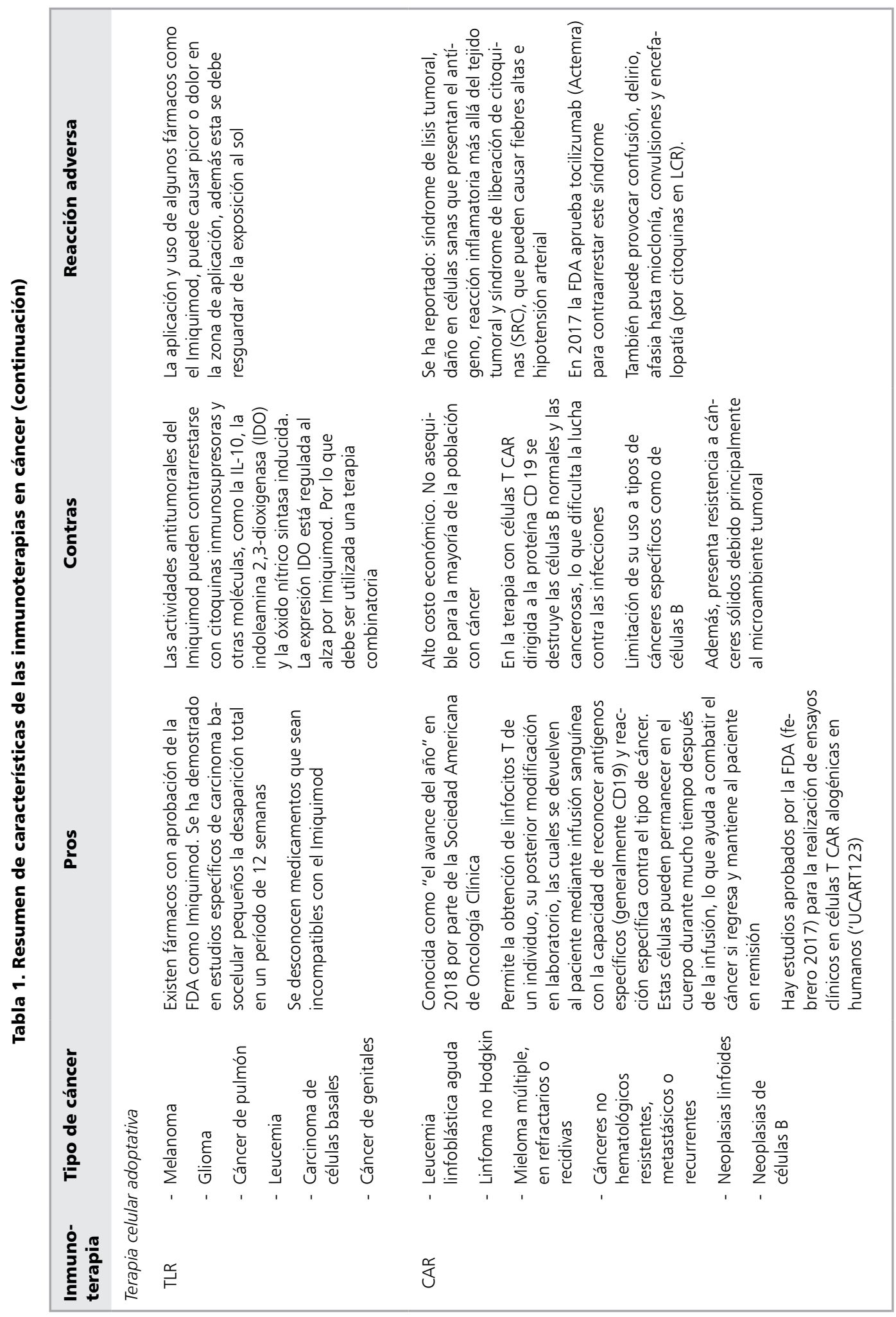




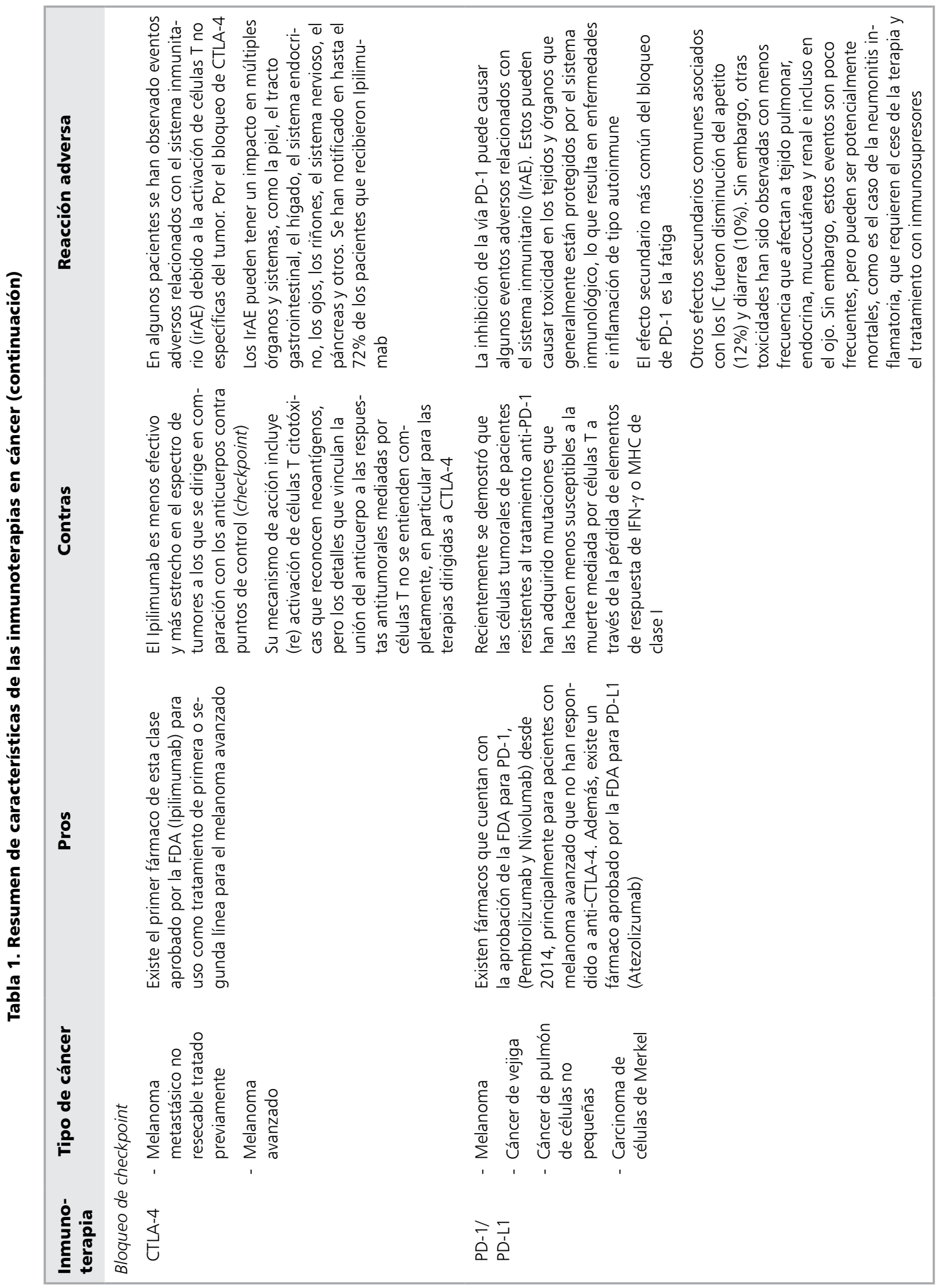


Cuando la vacuna para tratamiento está lista, se inyecta para aumentar la respuesta inmune contra las células cancerosas. Debido a la estimulación del sistema inmune y a que este posee células de memoria, se espera que la vacuna continúe funcionando después de la aplicación. Pero, se ha observado que su utilidad es limitada y en la actualidad casi no se utilizan ${ }^{19}$. Es el caso del cáncer pulmonar de células no pequeñas, donde estudios de fase III mostraron un buen nivel de toxicidad y tolerabilidad, sin embargo, no pudieron demostrar beneficios de supervivencia a pesar de los resultados que se lograron en los ensayos preliminares de fase $\mathrm{II}^{21}$. Sin embargo, para mejorar la efectividad de las vacunas, se han desarrollado varias estrategias. Por ejemplo: administrar la vacuna junto con un adyuvante, lo cual aumenta la respuesta inmune del huésped. Para evaluar la eficacia de combinar diferentes tratamientos contra el cáncer con vacunas, ya existen varios ensayos clínicos en curso.

Una de las pocas vacunas que está aprobada en Estados Unidos de Norteamérica es sipuleucel-T, vacuna de tipo autóloga, por lo que produciría una respuesta inmune específica contra este cáncer. Esta vacuna actúa en cáncer de próstata en etapa avanzada y se esperó que sirviera en otras etapas del mismo. Sin embargo, su utilidad fue muy limitada y actualmente casi no se utiliza ${ }^{19,20}$.

\section{Virus}

Se basa en la capacidad oncolítica de los virus por replicación selectiva en el tejido tumoral, lo que lleva a una potente respuesta inflamatoria en el microentorno tumoral. A medida que el sistema inmunitario elimina el virus, los puntos de control inmunitarios funcionan para suprimir la respuesta inflamatoria ${ }^{22}$.

Los virus oncolíticos son una plataforma altamente versátil para tratamiento del cáncer. La actividad antitumoral de virus oncolíticos implica múltiples mecanismos que abarcan las interacciones naturales entre los virus, células tumorales y el sistema inmunológico ${ }^{23}$. Los virus desarrollan mecanismos para evadir e interactuar con el sistema inmunológico, esto se utilizó con fines terapéuticos para inducir inmunidad antitumoral del huésped. La inyección local de virus oncolíticos en un solo sitio tumoral puede inducir un efecto abscopal, en el cual los tumores distantes no infectados también sufren un rechazo mediado por el sistema inmunitario. Este efecto abscopal ocurre a través de actividad gradual de virus oncolíticos, lo que resulta en liberación de antígenos y factores que promueven respuestas inmunitarias antitumorales innatas y adquiridas ${ }^{24}$.

Los virus oncolíticos pueden modificarse genéticamente para expresar genes terapéuticos que pueden mejorar aún más la actividad antitumoral. La expresión génica codificada por el virus en ausencia de replicación viral permite la modulación inmune contra tumores, y retrasa la respuesta inmune antiviral. Un ejemplo sería el uso de virus oncolíticos que expresan citoquinas de activación inmune, los cuales podrían modificar de manera óptima el microambiente y mejorar los efectos antitumorales ${ }^{23,24}$.

\section{Terapia celular adaptativa}

Debemos considerar que los linfocitos desempeñan un papel importante en la respuesta contra enfermedades, incluido el cáncer. Existen diferentes tipos de linfocitos, siendo los linfocitos T los involucrados en estas terapias.

Los linfocitos $\mathrm{T}$ se mueven hasta encontrar y destruir células defectuosas. Por ejemplo: un individuo entra en contacto con una nueva enfermedad, el cuerpo produce linfocitos T para combatirla. A continuación, mantiene una reserva, por si se encuentra nuevamente con el antígeno y así el organismo reconoce y ataca inmediatamente ${ }^{25,26}$.

La inmunoterapia que emerge a partir de este proceso se llama transferencia de células adaptativas (TCA), la cual consiste en recolección y uso de células inmunitarias de los pacientes para tratar el cáncer. Existen varios tipos de TCA ${ }^{25}$.

\section{- Linfocitos infiltrantes de tumores}

Esta terapia de transferencia (TIL; tumorinfiltrating lymphocyte) requiere aislamiento de linfocitos T a partir de biopsia frescas del paciente y selección progresiva de linfocitos $\mathrm{T}$ específicos del tumor ex vivo, utilizando altos niveles de IL-2 $y$ diversos enfoques de cultivo celular ${ }^{25,27}$.

Para estos tratamientos no se han informado efectos secundarios graves, solo náuseas y vómitos. Todos los demás eventos adversos fueron de grado 1 o 2 y se relacionaron con las inyecciones de IL-2 y no con TIL directamente ${ }^{27}$. 


\section{- Agonistas de receptores tipo Toll}

Esta terapia de transferencia (TLR; Toll-Like Receptor) pueden desencadenar respuestas inflamatorias que provocan una inmunidad innata rápida y promueven las actividades de linfocitos, lo que potencialmente puede mejorar la inmunoterapia adaptativa en el entorno del tumor ${ }^{25,28}$.

Cada infección tiene firmas moleculares únicas que son reconocidas por receptores tipo Toll, lo que resulta en activación de APC o coestimulación de linfocitos $\mathrm{T}$ que inducen inmunidad tanto innata como adquirida. Los TLR también participan en el desarrollo de linfocitos $\mathrm{T}$ y pueden reprogramar los linfocitos $\mathrm{T}$ reguladoras en linfocitos $\mathrm{T}$ auxiliares ${ }^{29,30}$.

\section{- Linfocitos T con receptores antigénicos quiméricos}

Esta terapia de transferencia proviene del uso de linfocitos $\mathrm{T}$ con receptores antigénicos quiméricos (CAR; Chimeric Antigen Receptor T cells), que consta de: porción extracelular, transmembrana e intracitoplasmática ${ }^{6}$. La porción extracelular reconoce al antígeno, mientras que el dominio intracitoplasmático es responsable de transducir señales de activación a través del receptor antigénico del linfocito T (TCR).

Basado en la variación de los dominios extracelulares, puede modificarse la especificidad del mismo, cambiando la especificidad de linfocitos $\mathrm{T}$, haciendo que sean específicos para la molécula que es reconocida por el dominio extracelular del $\mathrm{CAR}^{31}$. En Estados Unidos de Norteamérica se aprobó un tratamiento para niños con leucemia linfoblástica aguda (LLA) y otra para adultos con linfomas avanzados, ambos centrados en utilización de $\mathrm{CAR}^{32}$. En la terapia se separan los linfocitos $\mathrm{T}$, luego, utilizando un virus desensamblado, los linfocitos $\mathrm{T}$ son rediseñados genéticamente para producir receptores en superficie de tipo $\mathrm{CAR}^{33}$.

\section{Anticuerpos monoclonales inhibidores de puntos de control (checkpoint)}

Las células cancerosas inducen tolerancia de linfocitos $\mathrm{T}$ específicos mediante la expresión de ligandos que interaccionan con receptores inhibidores y amortiguan la función del linfocito $\mathrm{T}^{13}$. Una forma de combatir esto es con terapias de bloqueo de punto de control, que son las vías inhibitorias activadas por células cancerígenas ${ }^{34}$.
Un punto importante en el desarrollo de estos inhibidores es el hecho que la activación de linfocitos T requiere dos señales: 1) involucra el reconocimiento de antígenos específicos por los linfocitos, 2) involucra la existencia de señales inhibitorias negativas (coestimuladoras), siendo IL-12 e IFN $\alpha / \beta$ algunas de las principales fuentes de señal ${ }^{34}$.

Los linfocitos T citotóxicos (CTL), para reconocer y eliminar las células tumorales, requieren de dos fases de activación. La respuesta inmune temprana, en los ganglios linfáticos, se conoce como la fase de "cebado", que requiere de dos señales para la activación de linfocitos T. En la primera señal, los linfocitos T CD8+ reconocen los péptidos presentados por el complejo mayor de histocompatibilidad tipo I (MHC-I) en la superficie de células cancerosas a través del receptor de linfocitos T (TCR). La segunda señal, conocida como "señal coestimuladora" completa la activación de linfocitos $\mathrm{T}$ primarios, que se logra mediante la unión del receptor CD28 coestimulador de linfocitos $\mathrm{T}$ con los ligandos coestimulantes en células presentadoras de antígeno (APC): B7-1, B7-2 y PD-L1 ${ }^{34}$. Esto conduce a la fase de señalización descendente y activación de linfocitos $\mathrm{T}$, por mayor diferenciación en CTL. Cabe destacar que los linfocitos $\mathrm{T}$ CD8+ requieren una tercera señal, junto al antígeno y la coestimulación, para generar una respuesta productiva y evitar la inducción de muerte o tolerancia. Tras la activación, los CTL expresan receptores inhibitorios, CTLA-4 y PD-1 que funcionan como puntos de control inmunitarios ${ }^{35,36}$.

En condiciones normales, la unión de CTLA-4 con B7-1/2 contrarresta los efectos coestimulantes del CD28 en activación de células T, inhibiéndola. Los inhibidores del punto de control inmunitario más comunes son: antígeno asociado a los linfocitos $\mathrm{T}$ citotóxicos 4 (CTLA-4) y muerte programada 1 ( $\mathrm{PD}-1)$, este último interacciona con el ligando de muerte programada 1 (PD-L1) en APC o células tumorales ${ }^{34-36}$.

\section{Discusión}

Las inmunoterapias, al ser tratamientos que estimulan las propias defensas del paciente con cáncer, se han convertido en una alternativa real para enfrentar esta enfermedad. Estas técnicas se están probando con éxito en distintos tumores. 
En este sentido, se están desarrollando ensayos clínicos que se centran en diferentes enfoques terapéuticos sobre el sistema inmunológico. Aunque en la actualidad, el porcentaje de pacientes que no responden y el número de pacientes que presentan eventos adversos relacionados con el sistema inmunitario (Tabla 1) asociados con estos tratamientos ${ }^{5}$ sigue siendo alta. Por lo tanto, los esfuerzos se centran en mejorar la eficacia del tratamiento, haciéndolos más específicos o mediante uso de combinación de terapias o uso de agentes específicos, dirigidos molecularmente $e^{37,38}$.

Actualmente, existen algunas terapias por bloqueo de puntos de control que han comprobado ser efectivas contra el melanoma, cáncer de pulmón de células pequeñas y no pequeñas, cáncer de cabeza y cuello, cáncer de mama triple negativo, hepatocarcinoma, cáncer renal de células claras, cáncer de vejiga, tumores digestivos, entre otros. Algunas de ellas son ipilimumab, que bloquea CTLA-4; pembrolizumab que bloquea PD-1. O, Atezolizumab, bloquea PD-L1. Sin embargo, al ser un campo relativamente nuevo, otros fármacos se van produciendo, van pasando las diferentes fases clínicas y llegan a ser aprobados, los cuales se resumen en la Tabla $2^{39}$.

Tabla 2. Fármacos inmunoterapéuticos aprobados por FDA

\begin{tabular}{|c|c|}
\hline Fármaco & Inmunoterapia \\
\hline Pembrolizumab (Keytruda ${ }^{\circledR}$ ) & Inhibidor PD-1 \\
\hline Nivolumab (Opdivo ${ }^{\circledR}$ ) & Inhibidor PD-1 \\
\hline Ipilimumab (Yervoy $\left.{ }^{\circledR}\right)$ & Inhibidor CTLA-4 \\
\hline Atezolizumab (Tecentriq ${ }^{\circledR}$ ) & Inhibidor PD-L1 \\
\hline Durvalumab (Imfinzi $\left.{ }^{\circledR}\right)$ & Inhibidor PD-L1 \\
\hline Atezolizumab (Tecentriq ${ }^{\circledR}$ ) & Inhibidor PD-L1 \\
\hline IFN alfa & Citoquinas \\
\hline IL-2 & Citoquinas \\
\hline Talimogene laherparepvec (Imlygic $\left.{ }^{\circledR}\right)$ & Virus \\
\hline Bacille Calmette-Guerin (BCG) & Vacuna (citoquina) \\
\hline Imiquimod & Tópico (citoquina) \\
\hline Blinatumomab (Blincyto ${ }^{\circledR}$ ) & Inhibidor CD19 y CD3 \\
\hline Rituximab (Rituxan ${ }^{\circledR}$ ) & Inhibidor CD20 \\
\hline Obinutuzumab (Gazyva ${ }^{\circledR}$ ) & Inhibidor CD20 \\
\hline Ofatumumab (Arzerra ${ }^{\circledR}$ ) & Inhibidor CD20 \\
\hline Ibritumomab tiuxetan (Zevalin ${ }^{\circledR}$ ) & Inhibidor CD20 \\
\hline Lumoxiti (moxetumomab pasudotox ${ }^{\circledR}$ ) & Inhibidor CD22 \\
\hline Inotuzumab ozogamicina (Besponsa ${ }^{\circledR}$ ) & Inhibidor CD22 \\
\hline Brentuximab vedotin (Adcetris ${ }^{\circledR}$ ) & Inhibidor CD30 \\
\hline Alemtuzumab (Campath ${ }^{\circledR}$ ) & Inhibidor CD52 \\
\hline Polatuzumab vedotin-piiq (Polivy ${ }^{\circledR}$ ) & Inhibidor CD79b \\
\hline Talidomida $\left(\right.$ Thalomid $^{\circledR}$ ) & Inmunomodulador \\
\hline Lenalidomida $\left(\right.$ Revlimid $\left.^{\circledR}\right)$ & Inmunomodulador \\
\hline Axicabtagene ciloleucel (Yescarta ${ }^{\circledR}$ ) & Terapia adaptativa \\
\hline Tisangenlecleucel $\left(\right.$ Kymriah $\left.^{\circledR}\right)$ & Terapia adaptativa \\
\hline Sipuleucel-T (Provenge ${ }^{\circledR}$ ) & Terapia adaptativa \\
\hline
\end{tabular}

FDA: Administración de Alimentos y Medicamentos de los Estados Unidos de Norteamérica. 
Cabe mencionar que, dependiendo de la situación y aprobación oficial, los tratamientos inmunoterapéuticos pueden ser usados solos, en combinación con otras inmunoterapias o en combinación con algunos esquemas de quimioterapia citotóxica. Cuando estos tratamientos son usados en adyuvancia, conceptualmente se busca eliminar la enfermedad micrometastásica y así tener mayor sobrevida libre de recurrencia y sobrevida global. En casos de enfermedad metastásica, ya existen protocolos en curso de neoadyuvancia de quimioterapia citotóxica en combinación con inmunoterapia, los cuales están en fase de aprobación, buscando mayor resecabilidad y sobrevida libre de recurrencia y global. En pacientes con cáncer avanzado irresecable o que tienen metástasis se ha logrado aumento de sobrevida y calidad de vida, muchas veces con resultados inesperadamente favorables ${ }^{40}$.

En conjunto, todos los datos recopilados nos permiten sugerir a estas terapias como alternativa viable para ser utilizada, ya sea por si solas o de manera complementaria. Sin embargo, en algunos casos se están presentando indicaciones de ser tratamiento estándar, y ya no solo es considerado una sugerencia, sobre todo si consideramos que algunas secuencias de terapias en cáncer basadas en evidencia las incluyen en primera línea de tratamiento. Sin embargo, los costos siguen siendo elevados, sobre todo si consideramos el costo beneficio final ${ }^{41,42}$, donde muchos de estos fármacos son específicos no solo para el tipo de tumor, sino que para variaciones específicas de cada tumor, como para utilizarlos masivamente o para ser considerados como tratamiento de primera línea en algunos tipos de neoplasias. Ante esto, se hace imperativo generar nuevos proyectos de investigación que asocien ciencia básica, aplicada y estudios clínicos en inmunoterapia y cáncer, formando equipos multidisciplinarios y generando colaboraciones inter e intrainstitucionales, para resolver estas temáticas, y generar una disminución sustentable de los costos, privados y públicos de estos tratamientos ${ }^{43}$.

\section{Referencias}

1. Idikio HA. Human Cancer Classification: A Systems Biology-Based Model Integrating Morphology, Cancer Stem Cells, Proteomics, and Genomics [Internet]. J
Cancer 2011 [citado el 17 de abril de 2019].

2. Hanahan D, Weinberg RA. Review Hallmarks of Cancer: The Next Generation. Cell [Internet] 2011; 144 (5): 64674.

3. Baylin SB, Jones PA. A decade of exploring the cancer epigenome -biological and translational implications. Nat Rev Cancer 2011; 11(10): 726-34.

4. De Rosa M, Pace U, Rega D, Costabile V, Duraturo F, Izzo P, et al. Genetics, diagnosis and management of colorectal cancer (Review). Oncol Rep 2015; 34 (3): 1087-96.

5. Oiseth SJ, Aziz MS. Cancer immunotherapy: a brief review of the history, possibilities, and challenges ahead. J Cancer Metastasis Treat [Internet] 2017; 3 (10): 250 .

6. Meiliana A, Dewi NM, Wijaya A. Cancer Immunotherapy: A Review. Indones Biomed J [Internet] 2016; 8 (1): 1.

7. Parkin J, Cohen B. An overview of the immune system. Lancet (London, England) [Internet]. 2001; 357 (9270): 1777-89 [citado el 18 de abril de 2019].

8. Sánchez J, Cardona R, Caraballo L, Serrano C, Ramírez $\mathrm{R}$, Díez $\mathrm{S}$, et al. Inmunoterapia con alérgenos: mecanismos de acción, impacto terapéutico y socioeconómico Consenso de la Asociación Colombiana de Alergias, Asma e Inmunología. Biomédica [Internet] 2016; 36: 463-74 [citado el 16 de abril de 2019].

9. Chen DS, Mellman I. Elements of cancer immunity and the cancer-immune set point. Vol. 541, Nature. Nature Publishing Group; 2017. p. 321-30.

10. Minda AG, Awel FS, Seifudin KA, Gezahegne MK. Immunotherapy against cancer: A comprehensive review. J Cancer Res Exp Oncol [Internet] 2016; 8 (2): 15-25.

11. Farkona S, Diamandis EP, Blasutig IM. Cancer immunotherapy: The beginning of the end of cancer? BMC Med [Internet] 2016; 14 (1): 1-18.

12. Wang M, Yin B, Wang HY, Wang R-F. Current advances in T-cell-based cancer immunotherapy. Immunotherapy [Internet] 2014; 6 (12): 1265-78.

13. Lohmueller J, Finn OJ. Current modalities in cancer immunotherapy: Immunomodulatory antibodies, CARs and vaccines. Pharmacol Ther [Internet] 2017; 178: 3147 [citado el 18 de abril de 2019].

14. Berraondo P, Sanmamed MF, Ochoa MC, Etxeberria I, Aznar MA, Pérez-Gracia JL, et al. Cytokines in clinical cancer immunotherapy. Br J Cancer [Internet] 2019; 120 (1): 6-15 [citado el 17 de abril de 2019].

15. Boyman O, Sprent J. The role of interleukin-2 during homeostasis and activation of the immune system. Nat Rev Immunol [Internet] 2012; 12 (3): 180-90 [citado el 17 de abril de 2019]. 
16. Lee S, Margolin K. Cytokines in Cancer Immunotherapy. Cancers (Basel) [Internet] 2011; 3:3 856-93 [citado el 17 de abril de 2019].

17. Finn OJ. Cancer vaccines: between the idea and the reality. Nat Rev Immunol 2003; 3: 630-41.

18. Cancer vaccines $\mid$ American Cancer Society [Internet]. [citado el 17 de abril de 2019]. Available from: https:// www.cancer.org/treatment/treatments-and-side-effects/ treatment-types/immunotherapy/cancer-vaccines.html

19. Wong KK, Li WA, Mooney DJ, Dranoff G. Advances in Therapeutic Cancer Vaccines. Adv Immunol [Internet]. 2016; 130: 191-249 [citado el 18 de abril de 2019].

20. Li WA, Mooney DJ. Materials based tumor immunotherapy vaccines. Curr Opin Immunol [Internet]. 2013; 25 (2): 238-45 [citado el 18 de abril de 2019].

21. Oliveres H, Caglevic C, Passiglia F, Taverna S, Smits E, Rolfo C. Vaccine and immune cell therapy in non-sma$1 \mathrm{l}$ cell lung cancer. J Thorac Dis 2018; 10 (Suppl 13): S1602-14.

22. Liu Z, Ge Y, Wang H, Ma C, Feist M, Ju S, et al. Modifying the cancer-immune set point using vaccinia virus expressing re-designed interleukin-2. Nat Commun [Internet] 2018; 9 (1): 4682 [citado el 18 de abril de 2019].

23. Kaufman HL, Kohlhapp FJ, Zloza A. Oncolytic viruses: a new class of immunotherapy drugs. Nat Rev Drug Discov [Internet] 2015; 14 (9): 642-62 [citado el 18 de abril de 2019].

24. Bommareddy PK, Shettigar M, Kaufman HL. Integrating oncolytic viruses in combination cancer immunotherapy. Nat Rev Immunol [Internet] 2018; 18 (8): 498-513 [citado el 18 de abril de 2019].

25. June $\mathrm{CH}$. Adoptive $\mathrm{T}$ cell therapy for cancer in the clinic. J Clin Invest [Internet] 2007; 117 (6): 1466-76 [citado el 19 de abril de 2019].

26. Tran E, Robbins PF, Lu Y-C, Prickett TD, Gartner JJ, Jia L, et al. T-Cell Transfer Therapy Targeting Mutant KRAS in Cancer. N Engl J Med [Internet] 2016; 375 (23): 2255-62 [citado el 19 de abril de 2019].

27. Saint-Jean M, Knol A-C, Volteau C, Quéreux G, Peuvrel L, Brocard A, et al. Adoptive Cell Therapy with Tumor-Infiltrating Lymphocytes in Advanced Melanoma Patients. J Immunol Res [Internet] 2018; 2018: 3530148 [citado el 19 de abril de 2019].

28. Amos SM, Pegram HJ, Westwood JA, John LB, Devaud C, Clarke CJ, et al. Adoptive immunotherapy combined with intratumoral TLR agonist delivery eradicates established melanoma in mice. Cancer Immunol Immunother [Internet] 2011; 60 (5): 671-83 [citado el 19 de abril de 2019].

29. Braunstein MJ, Kucharczyk J, Adams S. Targeting
Toll-Like Receptors for Cancer Therapy. Target Oncol [Internet] 2018; 13 (5): 583-98 [citado el 6 de mayo de 2019].

30. Jin B, Sun T, Yu X-H, Yang Y-X, Yeo AET. The Effects of TLR Activation on T-Cell Development and Differentiation. Clin Dev Immunol [Internet] 2012; 2012: 1-32 [citado el 19 de abril de 2019].

31. Gamberale R. CAR T cells: Fundamentos de esta prometedora terapia inmunológica Chimeric antigen receptor T cells: conceptual basis of this promising immunological therapy [Internet]. 2014 [citado el 19 de abril de 2019].

32. Grupp SA, Kalos M, Barrett D, Aplenc R, Porter DL, Rheingold SR, et al. Chimeric Antigen Receptor-Modified T Cells for Acute Lymphoid Leukemia. N Engl J Med [Internet]. 2013; 368 (16): 1509-18 [citado el 19 de abril de 2019].

33. de Francisco ALM, Macía M, Alonso F, García P, Gutierrez E, Quintana LF, et al. Onco-Nefrología: cáncer, quimioterapia y riñón. Nefrología [Internet] 2019; Available from: https://linkinghub.elsevier.com/retrieve/ pii/S021169951930027X [citado el 5 de mayo de 2019].

34. Webb ES, Liu P, Baleeiro R, Lemoine NR, Yuan M, Wang Y. Immune checkpoint inhibitors in cancer therapy. J Biomed Res [Internet]. 2017; 0 (0): 1-10.

35. Boussiotis VA. Molecular and Biochemical Aspects of the PD-1 Checkpoint Pathway. N Engl J Med 2016; 375 (18): 1767-78. Available from: https://www.ncbi.nlm. nih.gov/pmc/articles/PMC5575761/pdf/nihms889103. pdf [citado el 21 de abril de 2019].

36. Zhao Y, Yang W, Huang Y, Cui R, Li X, Li B. Evolving Roles for Targeting CTLA-4 in Cancer Immunotherapy. Cell Physiol Biochem [Internet] 2018; 47 (2): 721-34 [citado el 19 de abril de 2019].

37. Gupta S, Gill D, Poole A, Agarwal N. Systemic immunotherapy for urothelial cancer: Current trends and future directions. Cancers (Basel) 2017; 9 (2): 1-14.

38. Azad NS, el-Khoueiry A, Yin J, Oberg AL, Flynn P, Adkins D, et al. Combination epigenetic therapy in metastatic colorectal cancer (mCRC) with subcutaneous 5 -azacitidine and entinostat; a phase 2 consortium/stand Up 2 cancer study. Oncotarget [Internet] 2015; 8 (21): 35326-38.

39. Coutzac C, Adam J, Soularue E, Collins M, Racine A, Mussini C, et al. Colon immune-related adverse events: Anti-CTLA-4 and anti-PD-1 blockade induce distinct immunopathological entities. J Crohn's Colitis. 2017; 11 (10): 1238-46.

40. Ott PA, Hodi FS, Kaufman HL, Wigginton JM, Wolchok JD. Combination immunotherapy: a road map. J Immunother Cancer 2017; 5: 16. [citado el 19 de abril 
de 2019]; Available from: https://jitc.biomedcentral. $\mathrm{com} / \mathrm{track} / \mathrm{pdf} / 10.1186 / \mathrm{s} 40425-017-0218-5$ ? site $=$ jitc. biomedcentral.com

41. Geynisman DM, Chien CR, Smieliauskas F, Shen C, Shih YCT. Economic evaluation of therapeutic cancer vaccines and immunotherapy: A systematic review. Hum Vaccines Immunother 2014; 10 (11): 3415-24.
42. Stambrook PJ, Maher J, Farzaneh F. Cancer Immunotherapy: Whence and Whither HHS Public Access. Mol Cancer Res [Internet] 2017; 15 (6): 635-50. Available from: https://www-ncbi-nlm-nih-gov.proxy.lib.fsu.edu/ pmc/articles/PMC5457704/pdf/nihms-848555.pdf.

43. Trapani JA, Darcy PK. Immunotherapy of cancer. Aust Fam Physician 2017; 46 (4): 194-8. 